\title{
Grupo Terapêutico em Sala de Espera: "Programa Tsurus e As Dobraduras da Vida"
}

\author{
Moreira, Samantha; Matosinho, Nívea Passos Maehara; Peeters, Irene da Silva \\ Icesp - Instituto do Câncer do Estado de São Paulo — samantha.moreira@icesp.org.br
}

Introdução: o diagnóstico de câncer e as mudanças decorrentes do adoecer e do tratamento podem despertar sentimentos de vulnerabilidade e insegurança nos pacientes e cuidadores. Frente ao tratamento quimioterápico geralmente surgirem preocupações referentes aos efeitos colaterais, dúvidas, fantasias e necessidade de adaptações. o cuidado psicológico durante a quimioterapia torna-se fundamental na mobilização de recursos de enfrentamento, sendo a intervenção em grupo e a arteterapia importantes ferramentas. Objetivo: Relatar a experiência do programa e refletir sobre os possíveis benefícios terapêuticos do recurso do origami em grupos de sala de espera. Método: Tratase de um grupo terapêutico aberto, coordenado por psicólogos, com frequência semanal, voltado principalmente aos acompanhantes de pacientes em tratamento quimioterápico. 0 convite é realizado na sala de espera do Setor de Quimioterapia. Podem participar homens, mulheres e crianças, sem restrições de idade. As atividades são semi-estruturadas: contase a história e a lenda que envolve o origami tsuru. em seguida, é ensinado como fazer a dobradura onde cada participante produz o seu próprio origami. Também é proporcionado um espaço de reflexão, discussão, atribuição de significados e acolhimento de conteúdos emocionais despertados a partir da atividade. Resultados: Desde o início do Programa, em 2009, participaram 46 pacientes e 1.995 acompanhantes. a maioria dos acompanhantes são mulheres e familiares de pacientes, refletindo o perfil dos cuidadores dos pacientes no hospital. a escolha do origami tsuru mostra-se favorecedor da expressão de sentimentos associados ao processo de adoecimento, pelo seu simbolismo e significado. o processo de transformação do papel, através das dobras, possibilita a reflexão sobre as mudanças e transformações na vida a partir da experiência da doença. Além disso, a lenda do tsuru incentiva o despertar de sonhos, fé e esperança. o grupo possibilita a troca de experiências, evidenciando a importância e necessidade de uma rede de apoio durante o momento vivenciado. a partir da atividade pode-se observar manifestações psíquicas e comportamentais de ansiedade, angústia, medo, fantasias, culpa, impotência, frustração, insegurança, bem como resiliência e esperança. Conclusão: o recurso artístico do origami em sala de espera surge como estratégia criativa e humanizadora na amenização do sofrimento frente ao adoecer. Esta intervenção parece favorecer o fortalecimento de recursos de enfrentamento dos participantes, possibilitando a expressão e elaboração de aspectos afetivos. Também estabelece um vínculo com o Serviço de Psicologia através do acolhimento e suporte psicológico aos usuários do Programa.

Moreira, Samantha; Matosinho, Nívea Passos Maehara; Peeters, Irene da Silva. Grupo Terapêutico em Sala de Espera: "Programa Tsurus e As Dobraduras da Vida". In: Anais do Congresso Internacional de Humanidades \& Humanização em Saúde [= Blucher Medical Proceedings, num.2, vol.1]. São Paulo: Editora Blucher, 2014. ISSN 2357-7282

DOI 10.5151/medpro-cihhs-10740 